\title{
Multidimensional diversity of bird communities across spatial variation of land cover in Zoige on the eastern Qinghai-Tibetan Plateau
}

\author{
Aichun $\mathrm{Xu}^{1 \dagger}$, Maojun Zhong ${ }^{2 \dagger}, \mathrm{Ke} \mathrm{Tang}^{2}$, Xiaoyi Wang ${ }^{2}$, Chen Yang ${ }^{2}$, Haigen $\mathrm{Xu}^{3}$, Jianfeng Yi ${ }^{3}$, Wei Liu ${ }^{3}$, \\ Chunlan Zhang ${ }^{4^{*}}$ and Junhua $\mathrm{Hu}^{2^{*}}$ (D)
}

\begin{abstract}
Background: Spatial variation of land cover can result in the changes of community similarities and biotic homogenization, whereby the increasing similarity would reduce the adaptive capacity of biotic assemblages to further disturbance, and degenerate ecosystem services they offer. However, it remains scarce to integrate multidimensional diversity for unveiling how variations in land cover may influence the patterns and processes of biotic homogenization in the Anthropocene. In this study, we examined how spatial variation of land cover could alter taxonomic, phylogenetic and functional homogenization of bird communities simultaneously in a compound ecosystem of Zoige Marsh on the eastern Qinghai-Tibetan Plateau. Acting as the largest alpine marsh and peatland in the world, Zoige Marsh has undergone great changes in the land cover pattern due to climate change and anthropogenic activities.

Methods: We conducted transect surveys for bird communities over six years (2014-2019) during breeding seasons in four main land cover types (meadow, woodland, village and marsh), representing the spatial variation of land covers in the study area. We compared multidimensional diversity (taxonomic, phylogenetic and functional diversity) among land covers to assess the effects of spatial variation in land cover type on bird communities, particularly whether this variation has homogenized biotic communities.

Results: Bird communities during breeding seasons were different and complementary in the four land covers. Taxonomic, phylogenetic and functional similarities were significantly lower in meadow than in the other three types, i.e. woodland, village and marsh. However, when we controlled for the effects of taxonomic similarities, the pattern of phylogenetic similarities almost reversed, with the highest standardized effect size (SES) phylogenetic similarity in meadow; and we found no significant difference in SES functional similarity among land covers.
\end{abstract}

\footnotetext{
*Correspondence: chunlanzh@qq.com; hujh@cib.ac.cn

${ }^{\dagger}$ Aichun Xu and Maojun Zhong contributed equally to the study

${ }^{2}$ Chengdu Institute of Biology, Chinese Academy of Sciences, Chengdu 610041, China

${ }^{4}$ Guangdong Key Laboratory of Animal Conservation and Resource Utilization, Guangdong Public Laboratory of Wild Animal Conservation and Utilization, Institute of Zoology, Guangdong Academy of Sciences, Guangzhou 510260, China

Full list of author information is available at the end of the article
}

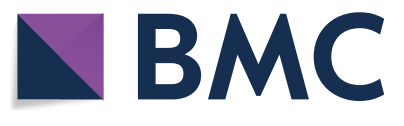

(c) The Author(s) 2021. This article is licensed under a Creative Commons Attribution 4.0 International License, which permits use, sharing, adaptation, distribution and reproduction in any medium or format, as long as you give appropriate credit to the original author(s) and the source, provide a link to the Creative Commons licence, and indicate if changes were made. The images or other third party material in this article are included in the article's Creative Commons licence, unless indicated otherwise in a credit line to the material. If material is not included in the article's Creative Commons licence and your intended use is not permitted by statutory regulation or exceeds the permitted use, you will need to obtain permission directly from the copyright holder. To view a copy of this licence, visit http://creativeco mmons.org/licenses/by/4.0/. The Creative Commons Public Domain Dedication waiver (http://creativecommons.org/publicdomain/ zero/1.0/) applies to the data made available in this article, unless otherwise stated in a credit line to the data. 
Conclusions: Our results suggest that spatial variation of land cover can play a crucial role in regulating multiple dimensions of bird diversity in Zoige Marsh. The findings indicate that taxonomic, phylogenetic and functional homogenization of bird communities may differently response to the variation of land covers. It thus highlights not only the relative roles of different land covers in maintaining biodiversity and community structures of birds, but also the urgency of retarding ecosystem degradations on the eastern Qinghai-Tibetan Plateau.

Keywords: Bird conservation, Biotic homogenization, Functional similarity, Land cover types, Phylogenetic similarity

\section{Background}

Anthropogenic activities, mainly land use change, can alter the nature habitats temporally, spatially, or both, and result in homogenized biological communities by bringing about similar environment (Olden 2006; IbáñezÁlamo et al. 2017; Liang et al. 2019). Available resources are usually different among land cover types, and variations in land cover may cause the homogenization of available resources which would cause local extirpations and even extinction of specialized species (those requiring particular habitat or food resources), while be beneficial to environmental generalists (those with less selective habitat or dietary needs) (Olden et al. 2004; de Castro Solar et al. 2015). This homogenizes the biota and further leads to serious ecological and evolutionary consequences, and is a huge challenge for biodiversity conservation (Olden 2006; van der Plas et al. 2016). A large number of studies have examined the effects of variations in land cover on diversity patterns for various taxa, and found different degrees of responses for biodiversity (Fernández-Juricic 2004; Peh et al. 2006; Weideman et al. 2020). Since the preservation of global biodiversity is one of the most important issues of both our time and the near future, understanding effects of variations in land cover on biodiversity to contribute to conservation strategies in the Anthropocene remains crucial (Jetz et al. 2007; Liang et al. 2020; Weideman et al. 2020).

To effectively protect biodiversity, conservation strategies are needed to not only focus on species diversity, but also pay close attention to evolutionary histories and ecological functions of target taxa (Faith 1992; Thuiller et al. 2011; Diniz-Filho et al. 2013; Mouillot et al. 2013; Tucker et al. 2017). Phylogenetic diversity can represent evolutionary history of biotic communities, reflecting evolutionary divergence and evolutionary richness (Faith 1992; Tucker et al. 2017). As differences in functional roles among taxa, functional diversity can be linked with environmental adaptations and ecosystem functioning (Petchey and Gaston 2006). Biotic communities with higher functional diversity may be more resilient to environmental changes than those lower (Mouillot et al. 2013). Consequently, integrating taxonomic, phylogenetic and functional diversity can gain a more comprehensive understanding of how variations in land cover would influence the patterns and processes of biotic homogenization (Liang et al. 2019; Weideman et al. 2020). Notably, even biotic homogenization can operate on multidimensional (e.g. taxonomic, phylogenetic and functional) diversity, the attempts to simultaneously assess how they respond to homogenization are relatively few (Liang et al. 2019).

Being the largest peat plateau bog in the world, Zoige (also named as Rouergai) Marsh (hereafter Zoige) provides many special functions of ecosystem service and can contribute to local climate regulation, and water and soil conservation. It is one of Chinese five largest rangelands via having a vast area of high-quality grasslands to provide huge quantity of fodder to livestock, and has the largest peat deposition in China. Acting as one of the hotspots for biodiversity, Zoige harbors a number of endemic and endangered species. Among them, 14 and 32 animal species have been respectively listed as national first- and second-class protected animals (Liu et al. 2009; Xiang et al. 2009; National Forestry and Grassland Administration and National Park Adiministration 2021). Actually, Zoige denotes a complex compound ecosystem with different types of land cover, e.g. freshwater marshes, meadows (grasslands), and sandy areas (the desertification area). Owing to unique climatic, geomorphologic and edaphic features, as well as various landscapes, Zoige is of great economic and ecological significance, being not only crucial to ecological security of the Yellow River drainage basin and the sustainable development of local people, but also a key region of global significance for biodiversity conservation (Xiang et al. 2009). However, due to climate change and increasing anthropogenic activities, such as ditching for grassland enlargement, peat exploitation, artificial drainage and over-grazing, severe ecosystem degradations have occurred in Zoige (Pang et al. 2010; Yu et al. 2017). In particular, being usually conducted to enlarge pastures and to tap peat resources, artificial drainage is often considered as the most important cause for the degradations (Xiang et al. 2009). Main degradations which include vegetation recessive succession, biodiversity loss, soil deterioration, and marsh degradation, are considered to be naturally irreversible and would seriously threaten biodiversity (Qian et al. 2002). Notably, the pattern of land 
covers in Zoige has undergone great changes in past several decades, with a sharp decrease in the wetland area (30-57\%), and most of the lost wetlands, having transformed into meadows, farmland or sandy lands (Pang et al. 2010; Shen et al. 2020). Moreover, not only temporal transformation of land covers, spatial characteristics of land degradation also deserves broader attention (Pang et al. 2010; Yu et al. 2017).

Birds are often regarded as appropriate bioindicators (Padoa-Schioppa et al. 2006; Hu et al. 2011). For birds in Zoige, previous studies focused on either waterbirds via one- or two-year surveys (Yang et al. 1997; Zhang et al. 2013), or the iconic species (i.e. the Black-necked Crane Grus nigricollis) (Jiang et al. 2014). But so far, no study of bird communities has conducted for the integrative ecosystem of Zoige across different land covers, especially considering the process of land degradation with spatial differences. In this study, based on a six-year continuous survey during breeding seasons, we explored multiple dimensions of diversity for bird communities in different types of land cover (i.e. with spatial variation across meadow, woodland, marsh and village) in Zoige. Specifically, we first characterized species richness patterns of birds for each land cover. Different land covers can lead to the difference in community similarities, depending on available resources. Next, we hypothesized that taxonomic, phylogenetic and functional similarities of bird communities in meadow were higher than those in other three land covers (woodland, marsh and village). We then examined the effects of taxonomic similarities on phylogenetic and functional similarities of bird communities among land covers. Through these efforts, our study can provide further insights into the effects of spatial variation of land cover on bird communities and provide helpful information for improving conservation in Zoige.

\section{Methods}

\section{Study area}

This study was conducted in the region of Zoige Marsh and the surrounding areas, within Zoige County, Sichuan Province, China (Fig. 1a). It is located on the eastern margin of Qinghai-Tibetan Plateau with an average elevation of $3500 \mathrm{~m}$ above sea level. The climate is mild, cold temperate continental monsoon type. It is characterized by short spring and autumn, cool mild summer, and a long, cold winter. The annual mean temperature is about 0.7 ${ }^{\circ} \mathrm{C}$, with monthly mean temperature extremes of $10.7^{\circ} \mathrm{C}$ and $-10.7{ }^{\circ} \mathrm{C}$ respectively in July and January. Annual precipitation is $656.8 \mathrm{~mm}(493.6-836.7 \mathrm{~mm}$ ) (Hao et al. 2008).

The study area is currently dominated by alpine meadows, and is rich in wild animals, with conservatively documented 137 bird, 38 mammal, 3 reptile, 15 fish, and 3 amphibian species (Xiang et al. 2009). Notably, for the Black-necked Crane, the only crane species breeding on the Qinghai-Tibetan Plateau, Zoige is one of main distribution areas and most important breeding sites in China (Jiang et al. 2014). To protect this integrative ecosystem and wildlife, a nature reserve was established in 1994 and designated a national reserve in 1998, and was listed as international importance by the Ramsar List of Wetlands in 2008. Yet, vast meadows are mainly used by local Tibetan pastoralists for grazing of yaks and sheep.

\section{Bird surveys}

We conducted field surveys for birds during breeding seasons continuously over 6 years, from May to July of 2014-2019. As an ecosystem complex of meadows, ponds, and marshes surrounded by low hills and river valleys, the study area includes four main land cover types, i.e. meadow, woodland, village and marsh (Fig. 1b). The classification of land covers was referred to remote sensing outputs (2015) (http://www.resdc.cn/data.aspx? DATAID =184). The transects for bird communities were set up to cover the four main land covers (Fig. 1b). Based on the extent of each type (Fig. 1b), we randomly selected ten transects to survey bird communities across four main land covers: six in meadow (mean length, $2.5 \mathrm{~km}$; $3415-3515 \mathrm{~m}$ a.s.l.), one in marsh $(2.5 \mathrm{~km}, 3440-3450 \mathrm{~m}$ a.s.l.), one in village ( $3.6 \mathrm{~km}, 3440-3510 \mathrm{~m}$ a.s.l.), and two in woodland (2.4 km and $2.1 \mathrm{~km}, 2910-3095 \mathrm{~m}$ a.s.l.). We recorded the locations of the start and end points of each transect using a handheld GPS and retained the aspects of the surveys across years (Fig. 1).

To detect as more species as possible, we surveyed each transect twice per year (one survey in May and the other one in July), resulting in a total of 12 surveys per transect across years. Average length of transects was $2.6 \mathrm{~km}(2-3.6 \mathrm{~km})$. For each survey, we recorded birds heard, seen in or hovering over transects. To avoid visibility problems, we conducted surveys referring to the technical guidelines for biodiversity monitoring-birds (HJ 710.4-2014), mainly between 30 min after dawn and 10:00 a.m., and between 3:30 p.m. and 30 min before sunset on fair weather days (i.e. no rainfall, fog or strong wind).

\section{Functional traits, phylogenetic and extinction risk data}

As functional traits, we considered body mass, trophic level, nest type and site (Si et al. 2017; Liang et al. 2019). These functional traits can act as the most important traits to be related to resource requirement and habitat use (Ding et al. 2013). We gathered functional data from fieldwork and the literature (Zhao 2001; Hao et al. 2008). We coded trophic level as omnivores (1), frugivore (2), insectivores (3), piscivores (4), and carnivores 


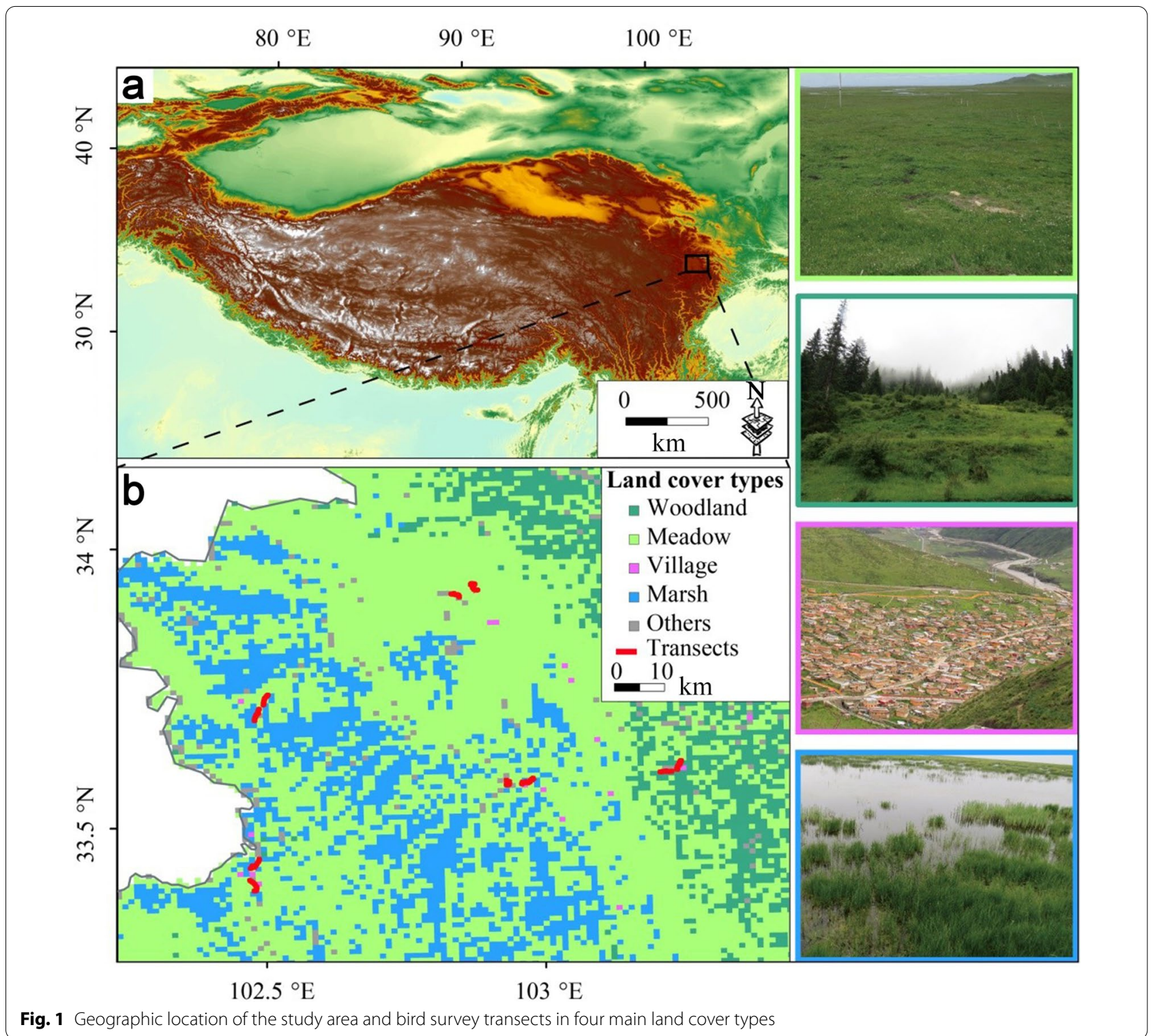

(5). We classified nest site as cavity (1), tree (2), shrub (3), water (4), and ground (5). We also classified nest type as exposed (1, i.e. no nest, platform, saucer, scrape) or unexposed (0) (Additional file 1: Table S1) (Si et al. 2017; Liang et al. 2019).

We downloaded a distribution of 5000 phylogenies for all species in this study from the global phylogeny of birds (Jetz et al. 2014). Based on this, we sampled 5000 pseudo-posterior distributions and constructed the Maximum Clade Credibility tree with mean node heights using TreeAnnonator v1.8.3 (Drummond and Rambaut 2007). We used the consensus phylogeny for subsequent analyses. We collected data on the threatened status of all recorded species based on both the Red List of China's
Vertebrates (Jiang et al. 2016) and the IUCN Red List (IUCN 2020) (Additional file 1: Table S1).

\section{Data analysis}

To assess whether bird communities during breeding seasons was adequately sampled for different habitats, we performed individual-based rarefaction analyses to estimate species richness based on abundance data in the iNEXT package (Hsieh et al. 2016). The rarefaction curves (including extrapolation) illustrated the completeness of survey inventories and the sufficiency of sampling efforts (Fig. 2a). We then used the VennDiagram package to illustrate species overlap among habitats based on the number of species recorded (Chen and Boutros 2011). 


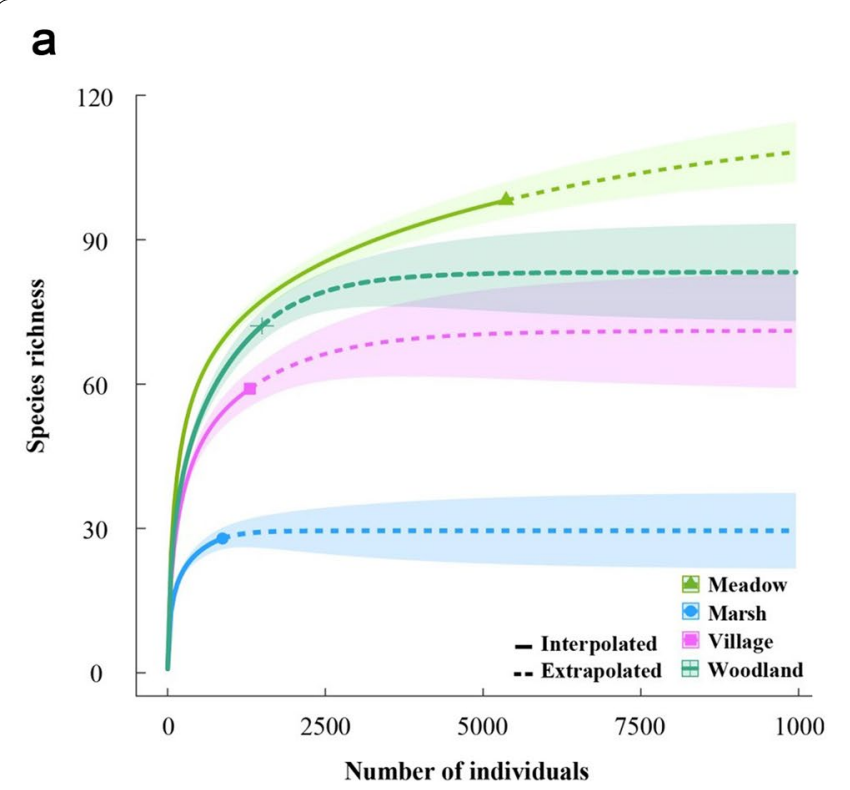

b

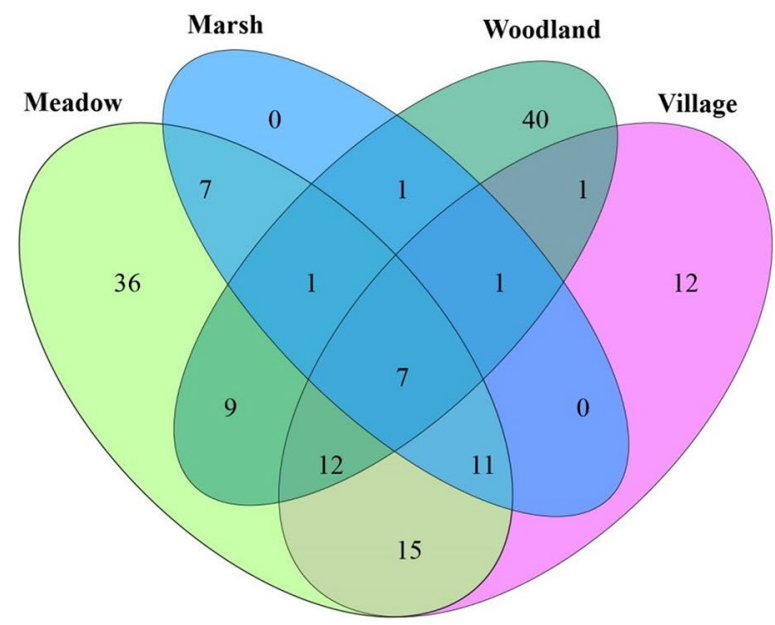

Fig. 2 a Individual-based rarefaction curves for estimating species richness of birds during breeding seasons in each land cover type ( $q=0)$. b Species overlap of birds among land covers, illustrated by a Venn diagram representing the number of species recorded

Using phylogenetic relatedness, we constructed a phylogenetic dendrogram. Since the functional trait matrix included both binary and continuous variables, we calculated the functional distance using the Gower's distance, and constructed a functional dendrogram using the 'complete' method of hierarchical clustering.

We used the Sørensen index to assess taxonomic similarity, representing the proportion of shared species to the total number of species occurred in two assemblages. We computed taxonomic similarity using the "betadiver" function in vegan package (Oksanen et al. 2019). To assess phylogenetic similarity among assemblages between transects in each land cover type over time, we then used the Phylosor index which represents the proportion of shared branch length to the total evolutionary branch length of two samples (Bryant et al. 2008). We also assessed functional similarity using the Phylosor index based on the functional dendrogram. We computed phylogenetic and functional similarities using the function "phylosor" in picante package. To compare taxonomic, phylogenetic and functional similarities among land covers, we conducted Tukey's multiple comparisons based on lmer models, using the "glht" function in multcomp package (Hothorn et al. 2008) and "lmer" in lme4 package (Bates et al. 2015).

Finally, to eliminate the effect of taxonomic similarities, we calculated the standardized effect size (SES) for phylogenetic and functional similarities of each assemblage. It was computed as $\mathrm{SES}_{\text {phylosor }}=\frac{\text { Phylosor }_{\text {obs }}-\text { mean Phylosor }}{\text { sd }}$, where Phylosor ${ }_{\text {obs }}$ was observed phylogenetic/functional
"Phylosor" similarities; mean Phylosor ${ }_{\text {rnd }}$ was mean "Phylosor" similarities of the null models, by shuffling species labels in community data while maintaining species richness and species shared between communities for 999 times; and sd Phylosor ${ }_{\text {rnd }}$ was the standard deviation of "Phylosor" similarities of the null models (Kembel et al. 2010). We calculated the 999 random phylogenetic and functional similarities using the "phylosor.rnd" function in picante package (Kembel et al. 2010). We used Tukey's multiple comparisons to examine the differences of the SES phylogenetic and functional similarities among land covers. We conducted all above analyses in $\mathrm{R}$ version 3.6.2 (R Core Team 2019).

\section{Results}

During breeding seasons, a total of 153 species and 9026 individuals (meadow, 5361 individuals; woodland, 1494 individuals; village, 1302 individuals; and marsh, 869 individuals) belonging to 17 families were recorded from the 6-year continuous surveys. Of these, even most species were least concern, 11 species were listed as endangered, vulnerable and near-threatened categories in China and/or the IUCN Red List (Fig. 3a, b; Additional file 1: Table S1). Specifically, 2 endangered (Falco cherrug, Mergus squamatus), 2 vulnerable (Aythya ferina, G. nigricollis), and 4 near-threatened (Aegypius monachus, A. nyroca, Gypaetus barbatus, Gyps himalayensis) species were listed in both China and the IUCN Red List. Another 3 species (Buteo hemilasius, Cygnus cygnus, Ithaginis cruentus) were designated as near-threatened 


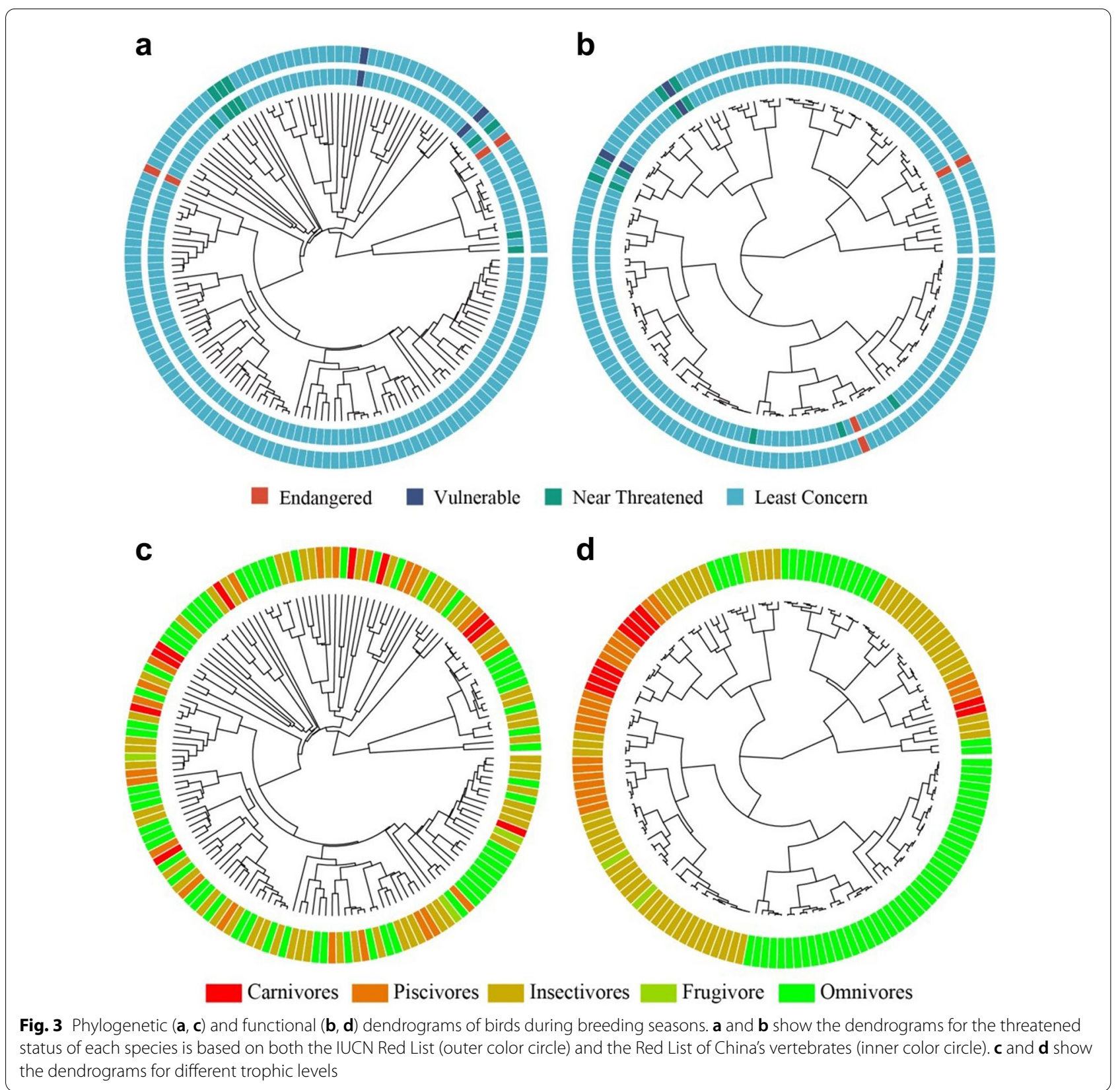

by the Red List of China's vertebrates but not by the IUCN Red List (Fig. 3a, b; Additional file 1: Table S1). Moreover, we showed the functional and phylogenetic dendrograms on trophic level (Fig. 3c, d).

Among land cover types (i.e. meadow, woodland, village and marsh), the highest species richness (98 species, $65 \%$ of the total species richness) were recorded in meadow, followed by woodland (72 species, $47 \%$ ), village (59 species, $39 \%$ ) and marsh ( 28 species, $18 \%$; Additional file 1: Table S1). Of all species recorded 36,40 and 12 species were found exclusively in meadow, woodland and village, respectively; while no species was found exclusively in marsh (Fig. 2b). Seven species were recorded across land covers (Fig. 2b), including B. buteo, B. hemilasius, M. merganser, Passer montanus, Phoenicurus ochruros, Pyrrhocorax pyrrhocorax and Turdus kessleri. The number of species that occurred in only a single land cover type accounted for $58 \%$ of the total number of species, and 19\% were found in more than 3 types (Fig. 2b; Additional file 1: Table S1).

Taxonomic similarity was significantly different among land covers (Fig. 4a; Table 1). For both phylogenetic and 


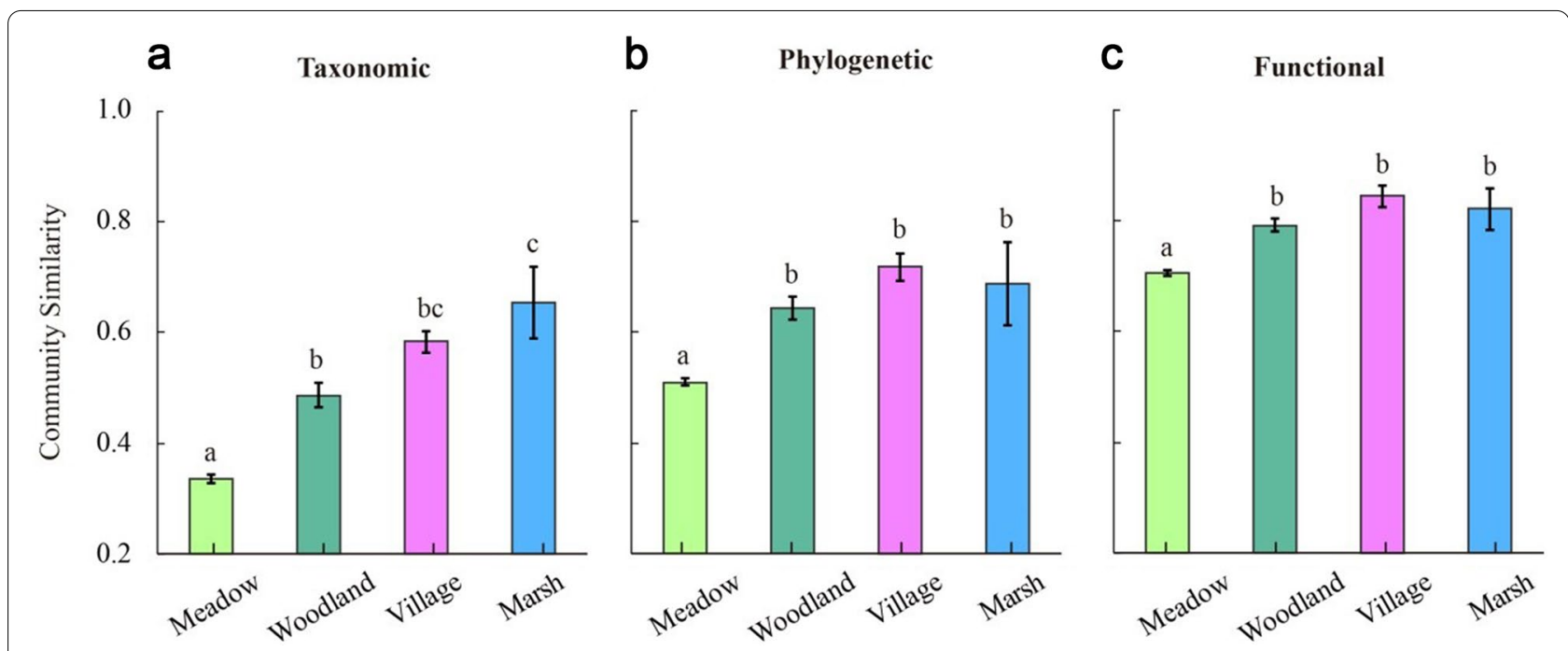

Fig. 4 Multiple comparisons for taxonomic, phylogenetic and functional similarities of bird communities in four land cover types. Different letters indicate significant difference among land covers $(P<0.05)$ based on Tukey's multiple comparisons. Error bars, \pm SE. The explanations apply also to Fig. 5

Table 1 Tukey's multiple comparisons for taxonomic, phylogenetic and functional similarities of bird communities in four main land cover types in Zoige

\begin{tabular}{|c|c|c|c|c|c|c|}
\hline & \multicolumn{2}{|c|}{ Taxonomic } & \multicolumn{2}{|c|}{ Phylogenetic } & \multicolumn{2}{|c|}{ Functional } \\
\hline & $z$ & $P$ & $z$ & $P$ & $Z$ & $P$ \\
\hline Meadow-Marsh & -4.928 & $<0.001$ & -3.396 & 0.003 & -3.181 & 0.006 \\
\hline Village-Marsh & -0.771 & 0.441 & 0.421 & 0.857 & 0.455 & 0.930 \\
\hline Woodland-Marsh & -2.426 & 0.045 & -0.792 & 0.857 & -0.731 & 0.930 \\
\hline Village-Meadow & 3.846 & $<0.001$ & 3.987 & $<0.001$ & 3.820 & $<0.001$ \\
\hline Woodland-Meadow & 5.501 & $<0.001$ & 6.020 & $<0.001$ & 5.665 & $<0.001$ \\
\hline Woodland-Village & -1.416 & 0.313 & -1.342 & 0.538 & -1.327 & 0.553 \\
\hline
\end{tabular}

functional similarities, meadow was significantly lower than other three types, and there was no significant difference among woodland, village and marsh (Fig. 4b, c; Table 1). Specifically, community similarity of multiple dimensions was the lowest in meadow $(0.34,0.51$ and 0.71 for taxonomic, phylogenetic and functional similarities, respectively). Yet, the highest taxonomic similarity was in marsh (0.65), and the highest phylogenetic and functional similarities were both in village (0.72 and 0.84 , respectively; Fig. 4).

Compared with phylogenetic similarity, SES phylogenetic similarity showed a nearly inverse pattern, with the highest similarity in meadow (2.16) and the lowest similarity in marsh $(-0.88)$ (Fig. 5a; Tukey's multiple comparisons, Meadow-Marsh: $Z=7.66, P<0.001$; Village-Meadow: $Z=-5.50, P<0.001$; Woodland-Meadow: $Z=-13.83, P<0.001$; other three pairs, $P>0.05$ ). Compared with functional similarity, SES functional similarity showed a similar pattern, with the highest value in village; however, no significant difference was found among land covers (Fig. 5b; Tukey's multiple comparisons, all $P>0.05)$.

\section{Discussion}

Our results reveal that meadow harbored most of endangered, vulnerable and near-threatened species, and highlight its important role in breeding bird diversity conservation in Zoige. Taxonomic, phylogenetic and functional similarities of bird communities during breeding seasons were all lower in meadow than in other three land covers, i.e. woodland, village and marsh, suggesting lowest homogenization in meadow among land covers. Moreover, we found the highest standardized effect size (SES) phylogenetic similarity in meadow when controlling for the effects of taxonomic similarity. 
a Phylogenetic

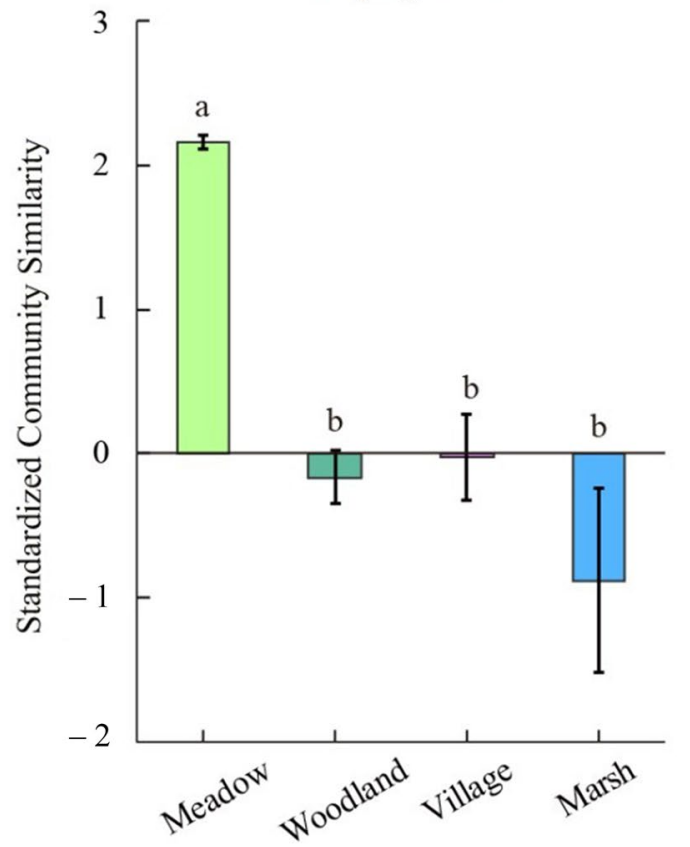

b Functional

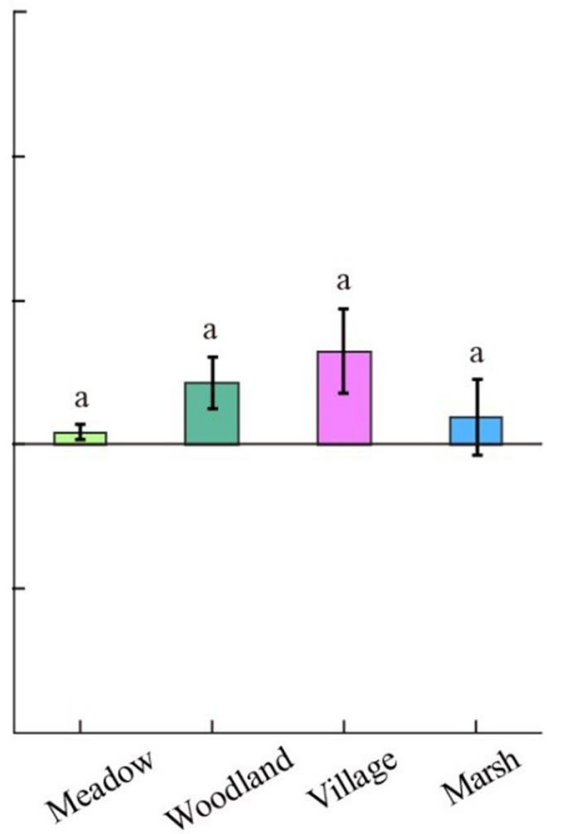

Fig. 5 Multiple comparisons for the standardized effect size of phylogenetic and functional similarities of bird communities in four land cover types

Spatial distribution of bird species and community composition are affected by many factors, including habitat type, the extent of human disturbance, and species' ability to adapt to habitat conditions (FernándezJuricic 2004; Peh et al. 2006; Liang et al. 2019). Based on the Venn diagram (Fig. 2b), we found a pattern of species complementarities among the four land covers during breeding seasons. This comparison suggested that a considerable number of species occurred exclusively in a single land cover, besides those inhabiting in no less than two types. As environmental conditions and vegetation structure of different transects varied among the four land covers, this can lead to diverse bird communities. Therefore, the four land covers in this study are complementary, and can provide extensive, varied living environments for birds.

In view of the complex and changeable relationships between land cover and biodiversity, evidence is accumulating to support biotic homogenization facing variations in land cover (de Castro Solar et al. 2015; Liang et al. 2019). Generally speaking, along with the variation of land cover, available resources may be altered, and cause the changings of producers (e.g. composition and biomass) and consumers within the ecosystem. For example, variations in land cover can benefit widespread species/generalists but negatively affect rare/endemic species, resulting in biotic homogenization by increasing taxonomic similarities across sites (McKinney 2006).
Specifically, biotic communities are most likely to become more homogenized in space and time when generalists frequently replace are species (McKinney 2006). Supporting these ideas, our results showed the lowest taxonomic similarity in meadow while the largest in marsh. This implies a significant difference in taxonomic homogenization among land covers. For birds in marsh, $>25 \%$ species were repeatedly recorded in $70 \%$ surveyed transects, and Montifringilla taczanowskii was observed in all transects (Additional file 1: Table S1). And, all species observed in marsh also occurred in other types (Fig. 2b). In contrast, for birds in meadow (98 species), only $10 \%$ reoccurred in $30 \%$ transects, and $>51 \%$ (50 species) are migrants. The high proportion of migrant species can result in high species turnover of bird communities. All these suggest relatively low taxonomic homogenization during breeding seasons in meadow among land covers in Zoige. Moreover, Brawn et al. (2001) suggested that $56 \%$ species in grassland declined significantly during 1966-1998. This further emphasizes the important role of meadow in the conservation of birds in Zoige.

Phylogenetic diversity is a natural phylogeny-based measure of biodiversity, by summing the branch lengths of species in phylogenetic dendrogram. Besides taxonomic similarity, variations in environmental conditions among land cover types would influence phylogenetic diversity, and sometimes may lead to phylogenetic homogenization via phylogenetic diversity 
loss and evolutionary distinctiveness reduction of bird assemblages (Frishkoff et al. 2014; Morelli et al. 2016; Karp et al. 2018; Weideman et al. 2020). Interestingly, our results support these findings but the details here are more complex. The results showed a pattern of significantly higher phylogenetic similarity in meadow than in other three types; however, the pattern of phylogenetic similarities among land covers almost reversed when controlling for the effects of taxonomic similarities (Figs. 4 and 5). This suggests phylogenetic homogenization of bird assemblages in meadow becoming stronger after controlling the effects of taxonomic similarities. Two lines of evidence support the reversed patterns. In fact, SES estimates the differences between the observed and expected values from null models, representing the extent of phylogenetic similarities but eliminating the effects of taxonomic similarities. Due to varying degrees of species overlap among land covers (Fig. $2 \mathrm{~b}$ ), the possible effects of taxonomic similarities on phylogenetic similarities would be discrepant. Additionally, for 153 species recorded in this study, the evolutionary history of each one is distinctive (Fig. 3a, b). Most species in meadow distributed in basal lineages while most species in woodland were in young lineages (Fig. 3a, b; Additional file 1: Table S1). For example, dominant species in the meadow, including $M$. ruficollis, $M$. taczanowskii, $P$. montanus, are from young lineages. Young lineages are considered to be able to better adapt to changing environmental conditions from variations in land cover than basal lineages (Frishkoff et al. 2014; Morelli et al. 2016; Liang et al. 2019). Thus, our results indicate that, besides meadow, other habitats can also play respective, important roles in maintaining and protecting phylogenetic diversity of birds in the complex compound ecosystem of Zoige.

Compared with taxonomic and phylogenetic homogenization (Frishkoff et al. 2014; Ibáñez-Âlamo et al. 2017; Karp et al. 2018), the two facts most often used to explore impacts of variations in land cover on bird biodiversity, functional homogenization has remained largely ignored (but see Devictor et al. 2008; Liang et al. 2019), even though it may possess more direct links with ecosystem functioning (Petchey and Gaston 2002, 2006). As the sums of the branch lengths of species in the functional dendrogram, functional diversity would generally increase when communities have more species and more branch lengths (Petchey and Gaston 2006). Variations in land cover could filter species with specific ecological traits and affect functional diversity (Newbold et al. 2013). When ecological specialists are replaced by generalists in bird communities due to the variation of land cover, functional homogenization would increase (Devictor et al. 2008; Liang et al. 2019). In this study, functional similarities of bird communities in meadow are (significantly) lower than other three land cover types whether or not controlling for the effects of taxonomic similarities (Figs. 4 and 5). Specifically, the mean functional distance between the nine most abundant species in meadow (Alauda gulgula, Cyanopica cyanus, Eremophila alpestris, Larus brunnicephalus, $M$. ruficollis, $M$. taczanowskii, P. montanus, Pseudopodoces humilis, Tringa totanus) and other species is 0.402 , being larger than the mean functional distance of all species pairs $(0.371)$.

The ecosystem deterioration of Zoige is characterized by significantly declined proportion of intact wetlands, meadow, rangeland and a considerable increase of degraded meadow and larger areas of sandy lands. To restore the degraded ecosystem in Zoige, birds can act as indicators of successful ecological restoration (Kentula 2000). In Zoige, a traditional emphasis of biodiversity conservation has focused on waterbirds, and yet, the entire suite of birds should be protected. Moreover, not only species richness, but also the rarity and endemism jointly determine the conservation value of biological communities (Hu et al. 2011). In this study, some bird species were found exclusively in a single land cover type, but not in two or more types. Besides meadow, other land covers in Zoige should also be considered when selecting areas for restoration and conservation. Notably, to effectively protect the Black-necked Crane, diverse habitats of the crane should be met (Xiang et al. 2009). Due to the conversion of marshes into meadows or sands during the last several decades, the original integrality of Zoige has been destroyed, with the increase of landscape fragmentation and the degradation of marshes (Pang et al. 2010). This could reduce the availability of suitable habitats for wetland-dependent birds. Fortunately, after the establishment of the nature reserve, more emphasis has been placed on ecological restoration and the environmental quality of Zoige has improved greatly (Xiang et al. 2009). To reduce any negative effect on birds and maintain the complexity of bird communities in Zoige, further degradation of the habitat must be minimized.

\section{Conclusion}

Our results highlight the crucial role of spatial variation of land cover in regulating multiple dimensions of bird diversity in Zoige on the eastern Qinghai-Tibetan Plateau. However, the results are based on a continuous survey of 6 years, and we should conduct regular long-term monitoring for birds in future. Even Zoige is considered to be of global significance for biodiversity conservation, with unique service functions, the biodiversity of Zoige would suffer a severe threat when the ecosystem deterioration is triggered 
by both anthropogenic activities and climate change (Xiang et al. 2009; Pang et al. 2010; Shen et al. 2020). This emphasizes not only the relative roles of different land covers in maintaining biodiversity and community structures of birds, but also the urgency of retarding ecosystem degradations in this region. Maximizing biodiversity is often an explicit or implicit goal of conservation. The priority for conserving bird diversity cannot, therefore, be based simply on the land cover with high value of only one facet of taxonomic, phylogenetic or functional diversity. In a word, our findings suggest that conservation efforts in Zoige should focus not only on species richness, but also on phylogenetic and functional diversity.

\section{Supplementary Information}

The online version contains supplementary material available at https://doi. org/10.1186/s40657-021-00259-4.

Additional file 1: Table S1. The occupancy and trait data of 153 bird species during breeding seasons in Zoige on the eastern Qinghai-Tibetan Plateau.

\section{Acknowledgements}

We would thank Donghan Hou, Yan Huang, Shengnan Yang, Can Wang, Xue Gou, Shupei Tang, Qian Zhong, Kai Zhang, Hualin Yang, Han Li, Chunpeng Guo, and Sihao Pu for their help in the fieldwork. We thank Xue Chen who allowed us to use the photograph of village in Fig. 1.

\section{Authors' contributions}

AX, CZ and JH conceived the study. AX, MZ, KT, XW, JY, WL and JH collected the data with assistance from $C Y, H X$ and $C Z$. AX, MZ and JH performed the analyses. AX, MZ and JH wrote the article with assistance from XW, CY, and CZ. All authors read and approved the final manuscript.

\section{Funding}

This study was supported by the National Natural Science Foundation of China $(31770568,32071544)$, the "Light of West China" Program of the Chinese Academy of Sciences (2019XBZG_XBQNZG_A_003), and the National Major Science and Technology Projects of China (2018YFC0507206).

\section{Availability of data and materials}

The datasets used in the present study are available from the corresponding author on reasonable request.

\section{Declarations}

\section{Ethics approval and consent to participate}

Our research adheres to local guidelines and appropriate ethical approval and licenses were obtained.

\section{Consent for publication \\ Not applicable.}

\section{Competing interests}

The authors declare that they have no competing interests.

\section{Author details}

${ }^{1}$ College of Life Sciences, China Jiliang University, Hangzhou 310018, China. ${ }^{2}$ Chengdu Institute of Biology, Chinese Academy of Sciences, Chengdu 610041, China. ${ }^{3}$ Nanjing Institute of Environmental Sciences,
Ministry of Ecology and Environment of China, Nanjing 210042, China. ${ }^{4}$ Guangdong Key Laboratory of Animal Conservation and Resource Utilization, Guangdong Public Laboratory of Wild Animal Conservation and Utilization, Institute of Zoology, Guangdong Academy of Sciences, Guangzhou 510260, China.

Received: 3 February 2021 Accepted: 11 May 2021

Published online: 22 May 2021

\section{References}

Bates D, Mächler M, Bolker BM, Walker SC. Fitting linear mixed-effects models using Ime4. J Stat Softw. 2015;67:1-48.

Brawn JD, Robinson SK, Thompson lii FR. The role of disturbance in the ecology and conservation of birds. Annu Rev Ecol Syst. 2001;32:251-76.

Bryant JA, Lamanna C, Morlon H, Kerkhoff AJ, Enquist BJ, Green JL. Microbes on mountainsides: contrasting elevational patterns of bacterial and plant diversity. P Natl Acad Sci USA. 2008;105(Suppl 1):11505-11.

Chen $\mathrm{H}$, Boutros PC. VennDiagram: a package for the generation of highlycustomizable Venn and Euler diagrams in R. BMC Bioinform. 2011;12:35.

de Castro Solar RR, Barlow J, Ferreira J, Berenguer E, Lees AC, Thomson JR, et al. How pervasive is biotic homogenization in human-modified tropical forest landscapes? Ecol Lett. 2015;18:1108-18.

Devictor V, Julliard R, Clavel J, Jiguet F, Lee A, Couvet D. Functional biotic homogenization of bird communities in disturbed landscapes. Global Ecol Biogeogr. 2008;17:252-61.

Ding Z, Feeley KJ, Wang Y, Pakeman RJ, Ding P. Patterns of bird functional diversity on land-bridge island fragments. J Anim Ecol. 2013;82:781-90.

Diniz-Filho JAF, Loyola RD, Raia P, Mooers AO, Bini LM. Darwinian shortfalls in biodiversity conservation. Trends Ecol Evol. 2013;28:689-95.

Drummond AJ, Rambaut A. BEAST: Bayesian evolutionary analysis by sampling trees. BMC Evol Biol. 2007;7:214

Faith DP. Conservation evaluation and phylogenetic diversity. Biol Conserv. 1992:61:1-10

Fernández-Juricic E. Spatial and temporal analysis of the distribution of forest specialists in an urban-fragmented landscape (Madrid, Spain): implications for local and regional bird conservation. Landsc Urban Plan. 2004;69:17-32.

Frishkoff LO, Karp DS, M'Gonigle LK, Mendenhall CD, Zook J, Kremen C, et al. Loss of avian phylogenetic diversity in neotropical agricultural systems. Science. 2014;345:1343-6.

Hao Y, Wang X, Liu S, Xie D, Zhao J, Li H. Biodiversity evaluation of Zoige wetland national nature reserve. Sci Soil Water Conserv. 2008;6(Suppl):35-40 (in Chinese).

Hothorn T, Bretz F, Westfall P. Simultaneous inference in general parametric models. Biom j. 2008;50:346-63.

Hsieh TC, Ma KH, Chao A. iNEXT: an R package for rarefaction and extrapolation of species diversity (Hill numbers). Methods Ecol Evol. 2016;7:1451-6.

Hu J, Jiang Z, Zhang C, Xiao F, Hu H. Bird diversity and the conservation value of a new Ramsar site: Guangdong Haifeng Wetlands. China Integr Zool. 2011;6:266-78.

Ibáñez-Álamo JD, Rubio E, Benedetti Y, Morelli F. Global loss of avian evolutionary uniqueness in urban areas. Glob Change Biol. 2017;23:2990-8.

IUCN. The IUCN red list of threatened species. 2020. http://www.iucnredlist. org/. Accessed 15 May 2020.

Jetz W, Wilcove DS, Dobson AP. Projected impacts of climate and land-use change on the global diversity of birds. PLoS Biol. 2007;5:e157.

Jetz W, Thomas GH, Joy JB, Redding DW, Hartmann K, Mooers AO. Global distribution and conservation of evolutionary distinctness in birds. Curr Biol. 2014:24:919-30.

Jiang Z, Li F, Ran J, Zhang B, Wang B, Zhang M, et al. Numbers and breeding success of Black-necked Cranes (Grus nigricollis) at Ruoergai Nature Reserve, Sichuan Province. Zool Res. 2014;35(Suppl 1):128-33 (in Chinese)

Jiang Z, Jiang J, Wang Y, Zhang E, Zhang Y, Li L, et al. Red list of China's vertebrates. Biodivers Sci. 2016;24:500-51 (in Chinese).

Karp DS, Frishkoff LO, Echeverri A, Zook J, Juárez P, Chan KMA. Agriculture erases climate-driven $\beta$-diversity in Neotropical bird communities. Glob Change Biol. 2018:24:338-49. 
Kembel SW, Cowan PD, Helmus MR, Cornwell WK, Morlon H, Ackerly DD, et al. Picante: R tools for integrating phylogenies and ecology. Bioinformatics. 2010;26:1463-4.

Kentula ME. Perspectives on setting success criteria for wetland restoration. Ecol Eng. 2000;15:199-209.

Liang C, Yang G, Wang N, Feng G, Yang F, Svenning J-C, et al. Taxonomic, phylogenetic and functional homogenization of bird communities due to land use change. Biol Conserv. 2019;236:37-43.

Liang D, Yang S, Pagani-Núñez E, He C, Liu Y, Goodale E, et al. How to become a generalist species? Individual niche variation across habitat transformation gradients. Front Ecol Evol. 2020;8:597450.

Liu Y, Sun Z, Zhao J, Wang X, Liu S, Zhang M, et al. Mammal survey of Ruoergai Wetland National Nature Reserve. Sichuan Sichuan J Zool. 2009:28:768-71.

McKinney ML. Urbanization as a major cause of biotic homogenization. Biol Conserv. 2006;127:247-60.

Morelli F, Benedetti Y, Ibáñez-Álamo JD, Jokimäki J, Mänd R, Tryjanowski P, et al. Evidence of evolutionary homogenization of bird communities in urban environments across Europe. Global Ecol Biogeogr. 2016;25:1284-93.

Mouillot D, Graham NAJ, Villéger S, Mason NWH, Bellwood DR. A functional approach reveals community responses to disturbances. Trends Ecol Evol. 2013;28:167-77.

National Forestry and Grassland Administration and National Park Adiministration. Official release of the updated List of Wild Animals under Special State Protection in China. 2021. http://www.forestry.gov.cn/main/586/ 20210208/095403793167571html. (in Chinese).

Newbold T, Scharlemann JPW, Butchart SHM, Şekercioğlu ÇH, Alkemade R, Booth $\mathrm{H}$, et al. Ecological traits affect the response of tropical forest bird species to land-use intensity. P Roy Soc B-Biol Sci. 2013;280:20122131.

Oksanen J, Blanchet FG, Friendly M, Kindt R, Legendre P, McGlinn D, et al. vegan: community ecology package. R package version 2.5-6. 2019. https://CRAN.R-project.org/package=vegan. Accessed 31 Dec 2019.

Olden JD. Biotic homogenization: a new research agenda for conservation biogeography. J Biogeogr. 2006;33:2027-39.

Olden JD, Poff NL, Douglas MR, Douglas ME, Fausch KD. Ecological and evolutionary consequences of biotic homogenization. Trends Ecol Evol. 2004;19:18-24.

Padoa-Schioppa E, Baietto M, Massa R, Bottoni L. Bird communities as bioindicators: the focal species concept in agricultural landscapes. Ecol Indic. 2006;6:83-93.

Pang A, Li C, Wang X, Hu J. Land use/cover change in response to driving forces of Zoige County, China. Procedia Environ Sci. 2010;2:1074-82.

Peh KSH, Sodhi NS, de Jong J, Sekercioglu CH, Yap CAM, Lim SLH. Conservation value of degraded habitats for forest birds in southern Peninsular Malaysia. Divers Distrib. 2006;12:572-81.
Petchey OL, Gaston KJ. Functional diversity (FD), species richness and community composition. Ecol Lett. 2002;5:402-11.

Petchey OL, Gaston KJ. Functional diversity: back to basics and looking forward. Ecol Lett. 2006;9:741-58.

Qian W, Weikai B, Zhaoli Y. Basic types and characters of the western Zoige meadows and their changes in recent decades. Chin J Appl Environ Biol. 2002:8:133-41 (in Chinese)

R Core Team. R: a language and environment for statistical computing. R Foundation for Statistical Computing. 2019.

Shen G, Yang X, Jin Y, Luo S, Xu B, Zhou Q. Land use changes in the Zoige Plateau based on the object-oriented method and their effects on landscape patterns. Remote Sens. 2020;12:14.

Si X, Cadotte MW, Zeng D, Baselga A, Zhao Y, Li J, et al. Functional and phylogenetic structure of island bird communities. J Anim Ecol. 2017:86:532-42.

Thuiller W, Lavergne S, Roquet C, Boulangeat I, Lafourcade B, Araujo MB. Consequences of climate change on the tree of life in Europe. Nature. 2011;470:531-4.

Tucker CM, Cadotte MW, Carvalho SB, Davies TJ, Ferrier S, Fritz SA, et al. A guide to phylogenetic metrics for conservation, community ecology and macroecology. Biol Rev Camb Philos Soc. 2017:92:698-715.

van der Plas F, Manning P, Soliveres S, Allan E, Scherer-Lorenzen M, Verheyen K, et al. Biotic homogenization can decrease landscape-scale forest multifunctionality. P Natl Acad Sci USA. 2016;113:3557-62.

Wang Q, Bao W, Yan Z. Basic types and characters of the western Zoige meadows and their changes in recent decades. Chin J Appl Environ Biol. 2002:8:133-41 (in Chinese).

Weideman EA, Slingsby JA, Thomson RL, Coetzee BTW. Land cover change homogenizes functional and phylogenetic diversity within and among African savanna bird assemblages. Landsc Ecol. 2020;35:145-57.

Xiang S, Guo R, Wu N, Sun S. Current status and future prospects of Zoige Marsh in Eastern Qinghai-Tibet Plateau. Ecol Eng. 2009;35:553-62.

Yang X, Dai B, Long T, Wang S, Zhang R, Xiong Q, et al. A survey of water fowls and predatory birds in the Ruoergai wetland. J Sichuan Teach Coll. 1997;18:10-3 (in Chinese).

Yu K, Lehmkuhl F, Falk D. Quantifying land degradation in the Zoige Basin, NE Tibetan Plateau using satellite remote sensing data. J Mt Sci. 2017;14:77-93.

Zhang G, Dai Q, Liu D, Hou Y, Lu J, Shen Y, et al. The seasonal dynamic on waterbird population at Ruoergai marshes. China Chin J Zool. 2013;48:742-9 (in Chinese).

Zhao Z. The handbook of the birds of China. Changchun: Jilin Science and Technology Publishing House; 2001. (in Chinese).
Ready to submit your research? Choose BMC and benefit from:

- fast, convenient online submission

- thorough peer review by experienced researchers in your field

- rapid publication on acceptance

- support for research data, including large and complex data types

- gold Open Access which fosters wider collaboration and increased citations

- maximum visibility for your research: over $100 \mathrm{M}$ website views per year

At BMC, research is always in progress.

Learn more biomedcentral.com/submissions 